ISSN 2466-2232

Online ISSN 2466-2100

\title{
$\mathrm{Ti}-6 \mathrm{Al}-4 \mathrm{~V}$ 의 AM에서 기계적 성질에 미치는 Interpass Peening의 영향
}

\author{
변 재 $^{*} \cdot$ 이 희 준** 조 상 명**,+ \\ *부경대학교 대학원 신소재시스템공학과 \\ **현대로템(주) 중기사업본부 \\ ***부경대학교 신소재시스템공학과
}

\section{The Effect of Interpass Peening on Mechanical Properties in Additive Manufacturing of Ti-6Al-4V}

\author{
Jae-Gyu Byun*, Hui-jun Yi** and Sang-Myung Cho***,†
}

*Dept. of Materials System Engineering, Graduate School, Pukyong National Univ., Busan 48547, Korea

**Defense Inducstrial Division, Hyundai Rotem Company, Changwon 51407, Korea

***Dept. of Materials System Engineering, Pukyong National University, Busan 48547, Korea

†Corresponding author : pnwcho@pknu.ac.kr

(Received April 4, 2017 ; Revised April 19, 2017 ; Accepted April 24, 2017)

\begin{abstract}
Ti-alloys have high specific strength and are widely used for the filed of space aeronautics plant. However, it is difficult to process Ti-Alloys due to its high yield strength and it cannot raise the machining speed because it has a possibility of catching fire while processing. In order to reduce the number of processes for the Ti-alloys, the researches related to Additive Manufacturing(AM) have been actively carried out at the moment. As for the initial stage of AM market related to Ti-alloys, it started to use the raw material of powder metal, and it is currently being developed based on welding.

In this study, Interpass peening reduced the size of the primary $\beta$ grain in the $z$-axis direction, increased the nucleation site of a-colony, and decreased the length and width of a laths as though interpass rolling. Interpass peening leads to an increase in yield/ultimate tensile strength without decrease elongation, resulting decrease in anisotropy of the material.
\end{abstract}

Key Words : Additive manufacturing, 3D printing, Peening, Mechanical property, GTAW

\section{1. 서 론}

Additive manufacturing(AM)은 $\mathrm{CAD}$ 도면의 정보 로 제품을 얇은 층의 형태로 연속적으로 적층하여 원하 는 형상의 제품을 만들어내 것으로 대중적으로는 3D printing이라고 불린다 ${ }^{1)}$. 금속AM은 첨가되는 재료의 형상에 따라 크게 분말/와이어 방식으로 나누어지게 되 며, Table 1은 금속AM의 분류를 나타내고 있다 ${ }^{2}$. 금 속AM은 제품의 형상과 비슷하게 적층함으로서 가공량
을 최소화 할 수 있으며, Ti, Inconel, STS 등 고가의 소재에 적합하다.

특히 $\mathrm{Ti}$ 합금은 높은 비강도를 가져 항공·우주, 플랜 트, 자동차 등의 분야에 널리 사용되고 있지만, 높은 항복강도로 인해 절삭가공이 어렵고 가공시 화재발생 위험으로 가공속도를 높이지 못해 가공량이 많아질수록 제조원가는 상승한다. 가공전 제품무게와 최종제품의 무 게의 비를 뜻하는 Buy To Fly(BTF)가 높아질수록 가 공량이 많아져 제조원가는 증가한다. BTF를 줄이기 위 하여 해외에서는 난가공성 소재인 $\mathrm{Ti}-6 \mathrm{Al}-4 \mathrm{~V}$ 의 $\mathrm{AM}$ 연 
Table 1 Classification of metal AM process ${ }^{2)}$

\begin{tabular}{|c|c|c|c|c|c|}
\hline & Material & Power source & Process & Company & Deposition rate \\
\hline \multirow{4}{*}{$\mathrm{PBF}$} & \multirow{8}{*}{$\begin{array}{l}\text { Powder } \\
\text { based }\end{array}$} & \multirow{3}{*}{ Laser } & SLS(Selective Laser Sintering) & $\begin{array}{l}\text { EOS, 3D systems, } \\
\text { TPM, Farsoon, etc. }\end{array}$ & $0.1 \sim 0.2 \mathrm{~kg} / \mathrm{h}$ \\
\hline & & & DMLS(Direct Metal Laser Sintering) & EOS & $0.1 \sim 0.2 \mathrm{~kg} / \mathrm{h}$ \\
\hline & & & SLM(Selective Laser Melting) & $\begin{array}{l}\text { SLM Solutions, 3D } \\
\text { systems, Realizer, } \\
\text { Concept laser, etc. }\end{array}$ & $0.1 \sim 0.3 \mathrm{~kg} / \mathrm{h}$ \\
\hline & & Electron beam & EBM(Electron Beam Melting) & ARCAM & $0.1 \sim 0.2 \mathrm{~kg} / \mathrm{h}$ \\
\hline \multirow{11}{*}{ DED } & & \multirow{4}{*}{ Laser } & LENS(Laser Engineered Net Shaping) & Optomec & $0.1 \sim 2 \mathrm{~kg} / \mathrm{h}$ \\
\hline & & & DMD(Direct Metal Deposition) & DM3D & $0.1 \sim 2 \mathrm{~kg} / \mathrm{h}$ \\
\hline & & & DMT(Direct Metal Tooling) & InssTek & $0.1 \sim 2 \mathrm{~kg} / \mathrm{h}$ \\
\hline & & & CLAD(Construction Laser Additive Direct) & $\mathrm{BeAM}$ & $0.1 \sim 2 \mathrm{~kg} / \mathrm{h}$ \\
\hline & \multirow{7}{*}{$\begin{array}{l}\text { Solid } \\
\text { filler } \\
\text { based }\end{array}$} & Electron beam & $\begin{array}{l}\text { EBAM(Electron Beam Additive } \\
\text { Manufacturing) }\end{array}$ & Sciaky & $\sim 9 \mathrm{~kg} / \mathrm{h}$ \\
\hline & & $\begin{array}{l}\text { GTAW, } \\
\text { GMAW arc }\end{array}$ & WAAM(Wire Arc Additive Manufacturing) & Cranfield Univ. & $\sim 4 \mathrm{~kg} / \mathrm{h}$ \\
\hline & & \multirow{2}{*}{ GMAW arc } & DML(Direct Metal Lamination) & MUTOH & $\sim 4 \mathrm{~kg} / \mathrm{h}$ \\
\hline & & & ADED(Arc Directed Energy Deposition) & EWI & $\sim 4 \mathrm{~kg} / \mathrm{h}$ \\
\hline & & \multirow{2}{*}{ Plasma arc } & IFF(Ion Fusion Formation) & Honeywell & $\sim 3 \mathrm{~kg} / \mathrm{h}$ \\
\hline & & & RPD(Rapid Plasma Deposition) & Norsk titanium & $\sim 6 \mathrm{~kg} / \mathrm{h}$ \\
\hline & & GTAW arc & STAM(Super-TIG Additive Manufacturing) & Super-TIG welding & $\sim 7 \mathrm{~kg} / \mathrm{h}$ \\
\hline
\end{tabular}

구가 활발히 진행 중이다 ${ }^{3-7)}$.

금속AM은 용융풀이 응고하면서 열이 전도되는 방향과 반대로 조직이 성장해 나간다. 이러한 epitaxial grain growth는 이전 층의 grain이 부분적으로 재용융되어 결정의 성장방향을 결정하는 예비 핵의 역할을 하고, 다 음 층의 grain 성장방향은 이전 층과 동일하게 된다.

Fig. 1은 Fude Wang 등8)이 Wire+Arc Additive Manufacturing(WAAM) 공정으로 $\mathrm{Ti}-6 \mathrm{Al}-4 \mathrm{~V}$ 을 적층

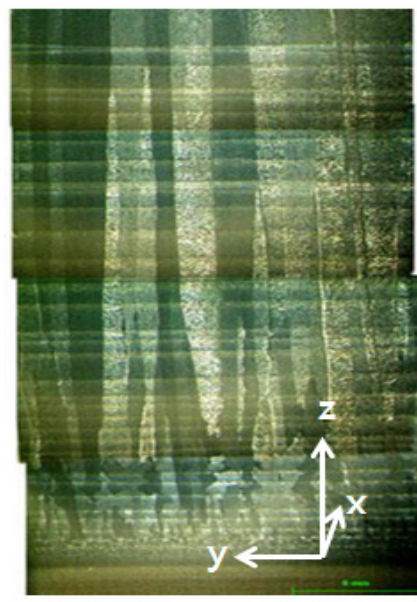

Fig. 1 Montage of macrostructure of pulse GTAW deposition Ti-6Al-4V wall $^{8)}$
하였을 때 나타난 단면으로서 $\mathrm{z}$ 축 방향으로 길게 성장 한 primary $\beta$ grain의 주상조직을 볼 수 있다. 이러 한 epitaxial grain growh로 인하여 적층 제품은 기 계적 성질의 방향성이 나타나게 된다. 금속 $\mathrm{AM}$ 에서 발 생하는 상기와 같은 기계적 성질의 방향성을 감소시킬 수 있는 공정 개발이 필요하다.

본 연구는 용착속도 TIG용접 아크를 열원으로 한 금 속 $\mathrm{AM}$ 에서 $\mathrm{Ti}-6 \mathrm{Al}-4 \mathrm{~V}$ 의 적층하여 $\mathrm{z}$ 축 방향의 기계적 성질을 $\mathrm{x}$ 축 방향과 동등수준으로 향상시키기 위하여 interpass peening의 영향을 검토하는 것을 목적으로 한다.

\section{2. 실험 방법}

\section{1 적층방법}

$\mathrm{TIG}$ 용접을 이용한 $\mathrm{Ti}-6 \mathrm{Al}-4 \mathrm{~V}$ 적층 실험은 기판모재 $200 \mathrm{~mm}(\mathrm{~L}) \times 100 \mathrm{~mm}(\mathrm{~W}) \times 2 \mathrm{~mm}(\mathrm{t})$ 의 ASTM Grarde 5 를 사용하였으며, 실험에 사용된 와이어는 $\Phi 1.2 \mathrm{ERTi}-5$ 를 사용하였다. 재료의 화학성분은 Table 2 와 Table 3 에서 표시하고 있다.

적층실험은 Fig. 2의 모식도와 같이 1layer 1pass 방식으로 비드폭은 약 $14 \mathrm{~mm}$, 층당 높이는 $1.5 \mathrm{~mm}$ 가 
Table 2 Chemical composition of base metal(ASTM Grade 5)

\begin{tabular}{|c|c|c|c|c|c|c|c|c|}
\hline & Ti & Al & V & Fe & N & C & H & O \\
\hline $\begin{array}{c}\text { Grade } \\
5\end{array}$ & Bal. & $5.5 \sim$ & $3.5 \sim$ & Max & Max & Max & Max & Max \\
& 6.75 & 4.5 & 0.40 & 0.05 & 0.08 & 0.015 & 0.20 \\
\hline
\end{tabular}

Table 3 Chemical composition of filler metal(AWS ERTi-5)

\begin{tabular}{|c|c|c|c|c|c|c|c|c|}
\hline & $\mathrm{Ti}$ & $\mathrm{Al}$ & $\mathrm{V}$ & $\mathrm{Fe}$ & $\mathrm{N}$ & $\mathrm{C}$ & $\mathrm{H}$ & $\mathrm{O}$ \\
\hline $\begin{array}{c}\text { Grade } \\
5\end{array}$ & Bal. & $5.5 \sim$ & $3.5 \sim$ & Max & Max & Max & Max & $0.12 \sim$ \\
& 6.75 & 4.5 & 0.22 & 0.03 & 0.05 & 0.015 & 0.20 \\
\hline
\end{tabular}

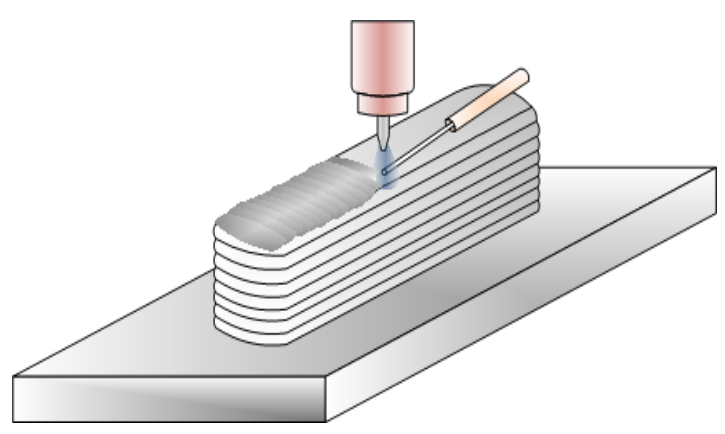

Fig. 2 Schematic of deposition 1layer 1pass Ti-6Al-4V

되도록 설계하여 층간온도를 $150^{\circ} \mathrm{C}$ 로 유지하면서 적층 하였다. 각 시험편당 최종 높이가 약 $100 \mathrm{~mm}$ 가 되도록 설계하여 70layer를 적층하였다.

$\mathrm{AM}$ 적층 조건은 Table 4 에 나타냈다. $190 \mathrm{~A}$ 의 전 류로 약 $1.0 \mathrm{~kg} / \mathrm{h}$ 의 적층속도로 적층을 하였고 벽면 끝 에서의 용융풀 흘러내림을 방지하기 위하여 오실레이션 을 사용하였다. Ti- $6 \mathrm{Al}-4 \mathrm{~V}$ 적층 시에 자주 발생하는 표 면산화 방지를 위하여 trail shielding 장치를 사용하

Table 4 Condition of AM

\begin{tabular}{|c|c|}
\hline Base metal & Ti Gr. $5(100 \times 200 \times \mathrm{t} 2)$ \\
\hline Filler metal & $\varnothing 1.2$ ERTi-5 \\
\hline Stand off & $4 \mathrm{~mm}$ \\
\hline Current & $190 \mathrm{~A}$ \\
\hline Welding speed & $18 \mathrm{~cm} / \mathrm{min}$ \\
\hline Shielding gas & Ar100\% $(20 \ell / \mathrm{min})$ \\
\hline Feed rate & $331 \mathrm{~cm} / \mathrm{min}$ \\
\hline Deposition area & $20.8 \mathrm{~mm}{ }^{2}$ \\
\hline Deposition rate & $1.0 \mathrm{~kg} / \mathrm{h}$ \\
\hline OS Frequency & $1.8 \mathrm{~Hz}$ \\
\hline Dwell time & $0.1 \mathrm{~s}$ \\
\hline Deposition method & 1 layer $1 \mathrm{pass}$ \\
\hline
\end{tabular}
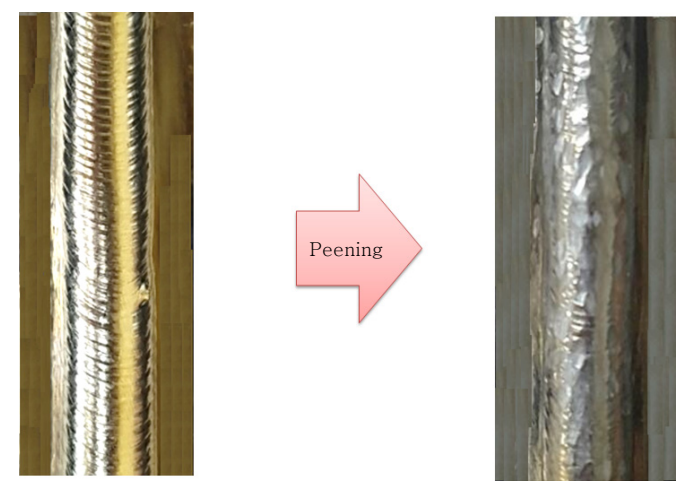

Fig. 3 Before/after bead appearance of as-deposited Ti-6Al$4 \mathrm{~V}$ by interpass peening

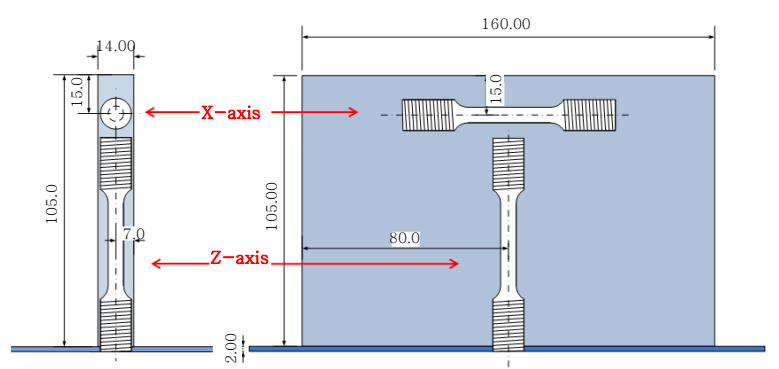

Fig. 4 Schematic diagram of collected location of tensile test specimen

였다. 단면 에칭은 $1.5 \% \mathrm{HF}+4.5 \% \mathrm{HNO}_{3}+$ 증류수 혼 합용액을 사용하여 30 초 동안 부식시켜 미세조직을 검 토하였다.

\subsection{Interpass peening 방법}

Ti-6Al-4V을 적층할 때 hammer peening machine 으로 층마다 용접비드 표면에 peening을 적용하였다. Fig. 3과 같이 적층이 끝나고 나면 표면산화 없는 반짝 반짝하고 매끄러운 표면이 나타나고 소성변형으로 인해 울퉁불퉁하게 되도록 표면 전체를 peening하여 다음 층을 적층하였다.

\section{3 시험편 채취위치}

Ti-6Al-4V 적층물의 Interpass peening 적용 여부에 따라서 Fig. 4의 모식도와 같이 X, z축으로 각각 인장 시험편을 채취하였다.

\section{3. 결과 및 고찰}

\subsection{Ti-6Al-4V 적층물 외관 및 단면}

\subsubsection{Ti-6Al-4V without peening}

Peening을 적용하지 않고 1layer 1pass의 방법으로 70 층을 적층한 적층물의 외관과 단면을 각각 Fig. 5 , 


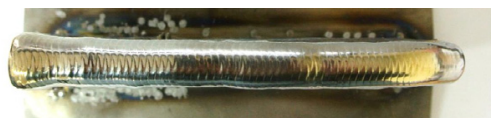

(a) Top view

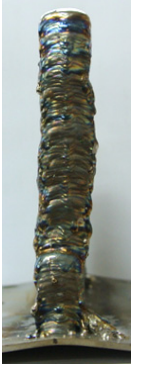

(b) Front view

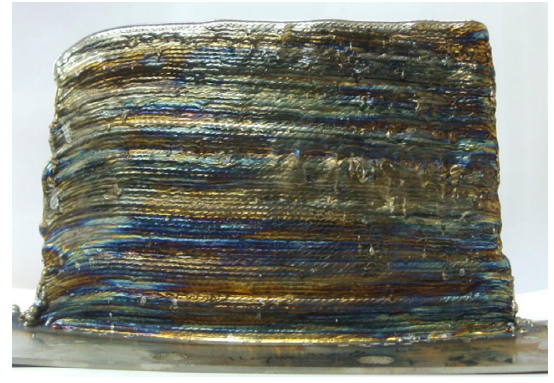

(c) Side view

Fig. 5 Appearance of Ti-6Al-4V deposition without peening

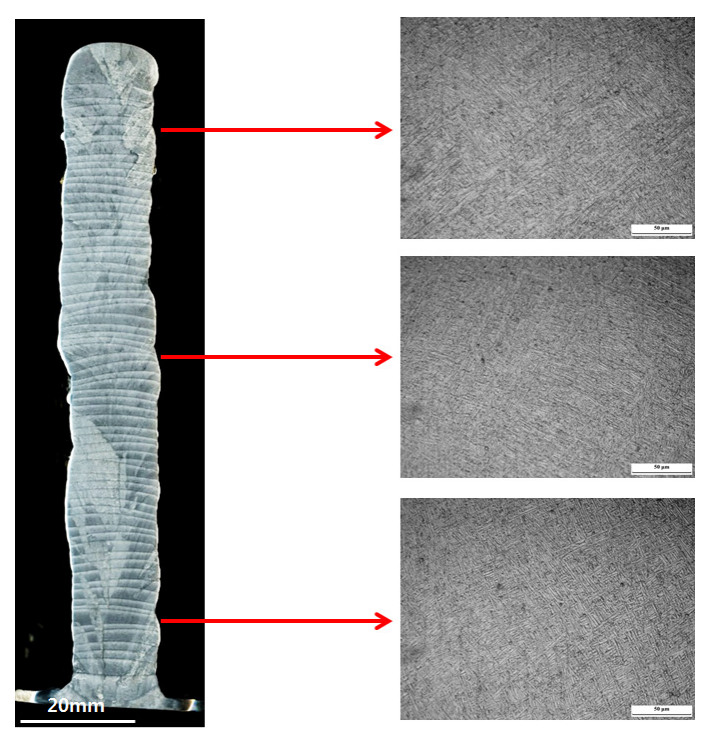

Fig. 6 Cross section and microstructure of Ti-6Al-4V deposition without peening

Fig. 6에 나타내었다.

매크로 단면사진에서 주상정이 $\mathrm{z}$ 축 방향으로 성장한 모 습을 확인할 수 있다. 위치에 관계없이 전체적으로 $\mathrm{Wid}^{-}$ manstatten $a$ 상과 길쭉한 colony $a$ 상이 혼합되어 나 타는 것을 확인하였다.

\subsection{2 $\mathrm{Ti}-6 \mathrm{Al}-4 \mathrm{~V}$ with peening}

1layer 1pass로 interpass peening을 적용한 적층 물의 외관과 단면은 Fig. 7, Fig. 8에 각각 나타내었다. 폭이나 높이에서 큰 차이가 없으나 단면에서 거대한 주 상정이 감소되고 미세화된 $\beta$ grain을 확인 할 수 있 었다.

미세조직은 전체적으로 위치에 관계없이 Widmanstatten $a$ 상이 나타났다.

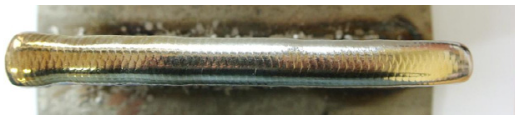

(a) Top view

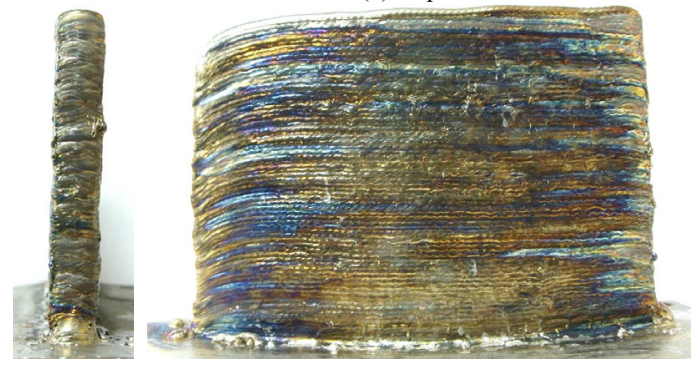

(b) Front view

(c) Side view

Fig. 7 Appearance of Ti-6Al-4V deposition with peening

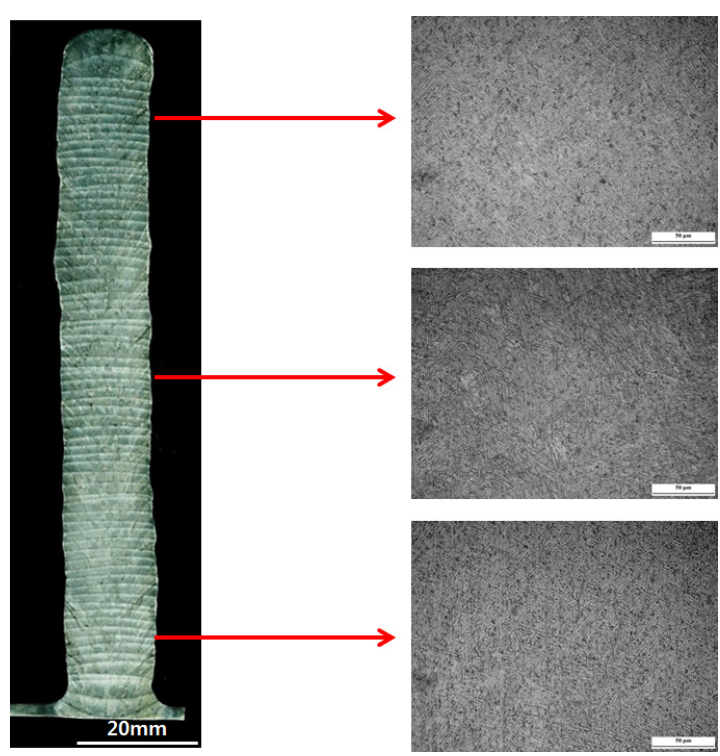

Fig. 8 Cross section and microstructure of Ti-6Al-4V deposition with peening

3.2 Interpass plastic working에 따른 Ti-6Al-4V 적층물의 기계적 성질 검토

Fig. 9에 전체적인 항복/인장강도를 비교하여 나타내 었다. 항복/인장강도는 $\mathrm{X}$ 축에 비하여 $\mathrm{Z}$ 축이 감소하는 경향이 나타났고, 이는 $\mathrm{Z}$ 축으로 길게 성장하는 주상정 의 영향으로 판단된다. Peening을 적용하지 않은 적층 물의 $\mathrm{x}$ 축 시험편은 항복/인장강도 모두 $\mathrm{AWS} \mathrm{spec.을}$ 만족했지만, $\mathrm{Z}$ 축 시험편은 항복/인장강도가 현저히 감 소하여 AWS spec.에 만족하지 못하였다.

반면에 층마다 peening을 적용한 적층물의 시험편은 항복/인장강도가 기존에 비하여 전체적으로 증가하였고, $\mathrm{Z}$ 축에서의 항복/인장강도가 $\mathrm{x}$ 축과 비슷하게 유지되어 $\mathrm{x}$ 축 과 $\mathrm{z}$ 축 시험편모두 $\mathrm{AWS} \mathrm{spec.을} \mathrm{만족하였다.}$

Fig. 10에 나타낸 연신율의 경우는 모든 시험편이 AWS 


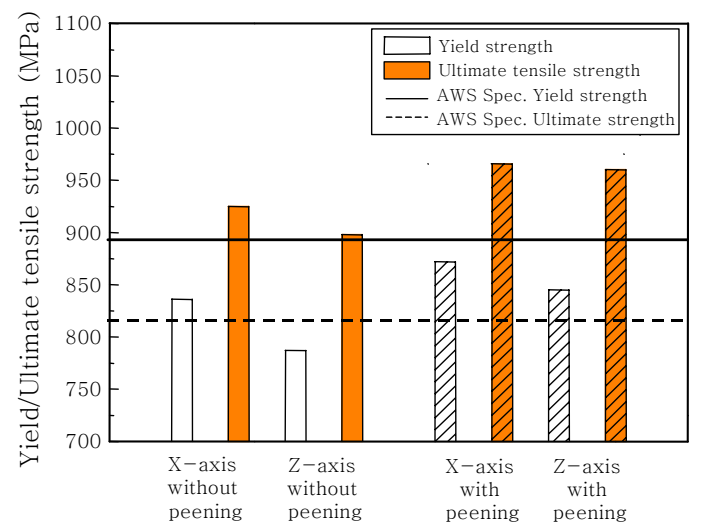

Fig. 9 Comparison of yield/ultimate tensile strength by deposition method and axis

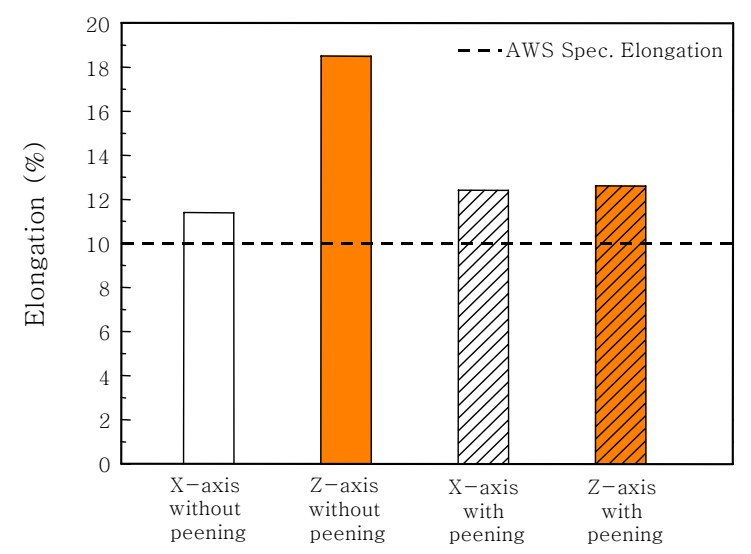

Fig. 10 Comparison of elongation by deposition method and axis

spec.을 만족하였으며 peening을 적용하지 않은 $z$ 축의 시험편에서 가장 높은 연신율 값을 얻을 수 있었다. 이는 $\mathrm{Z}$ 축의 항복강도 저하에 의한 연성증가로 나타난 결과라고 판단된다. $x$ 축의 경우는 peening을 적용한 시험편에서 연신율이 소폭 증가하였다.

Fig. 11은 Martina 등')에 의해 rolling 히중을 $0,50 \mathrm{kN}$, $75 \mathrm{kN}$ 세 가지 조건으로 적층한 $\mathrm{Ti}-6 \mathrm{Al}-4 \mathrm{~V}$ 적층물의 기 계적 성질을 비교한 그래프이다. Vertical ( $\mathrm{z}^{-}$-axis) 방향과 horizontal (x-axis) 방향 모두 rolling 하중이 증가할수록 항복/인장강도가 증가하는 경향을 보였다.

연신율은 horizontal 방향의 경우 하중 $50 \mathrm{kN}$ 에서 소 폭 감소하였다가 $75 \mathrm{kN}$ 에서는 다시 증가하였고, Vertical 방 향의 경우 rolling 하중이 증가할수록 연신율이 감소하는 것을 볼 수 있다.

Vertical 방향과 horizontal 방향의 기계적 성질을 비 교해보면 rolling을 하면 항복/인장강도, 연신율이 거의 비 슷한 값을 가지면서 본 연구의 interpass peening과 유 사하게 재료의 이방성이 없어지는 것을 볼 수 있다.

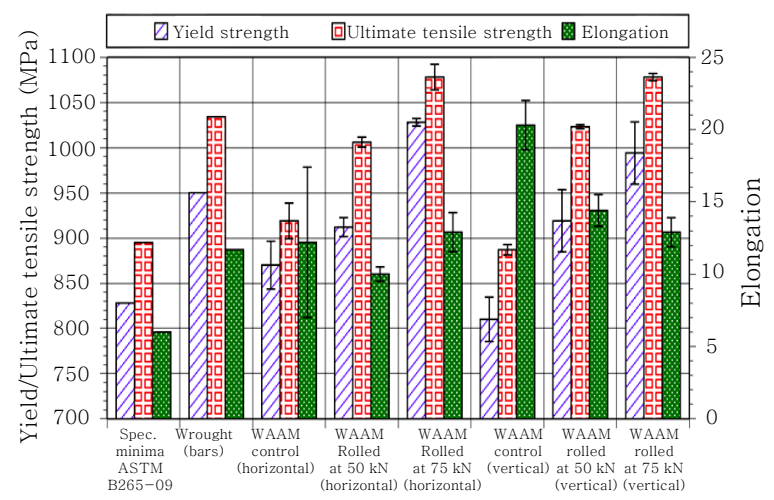

Fig. 11 Comparison of rolled WAAM specimens against unrolled ones (error bars indicate standard deviation), specification minima, and wrought Ti-6Al- $4 \mathrm{~V}^{9)}$

\subsection{Interpass plastic working에 따른 Ti-6Al-4V 적층물의 미세조직 검토}

\subsubsection{Primary $\beta$ grain size 비교}

Ti-6Al-4V의 금속 AM에서 Alphons Anandaraj 등 $^{10)}$ 은 Fig. 12 와 같이 interpass rolling 하중에 따른 미세조직을 관찰하였고, Colegrove 등11-12)은 Table 5와 같이 rolling 하중에 따른 primary $\beta$ grain 크기와 a lath 길이를 측정하였다.

Fig. 13은 본 연구에서 primary $\beta$ grain 크기를 비 교하기 위하여 광학현미경으로 촬영한 $\mathrm{Ti}-6 \mathrm{Al}-4 \mathrm{~V}$ 적층 물의 미세조직이다. Table 6 은 $\beta$ grain 크기를 나타낸 것이며, $\mathrm{Ti}-6 \mathrm{Al}-4 \mathrm{~V}$ 금속 $\mathrm{AM}$ 시에 interpass peen-
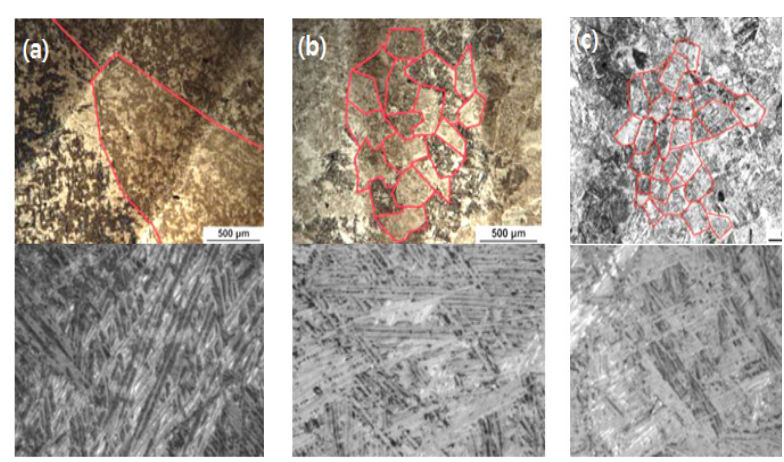

Fig. 12 Optical and SEM microstructure of as deposited Ti-6Al-4V from (a) as-built, (b) rolled at $50 \mathrm{kN}$, (c) rolled at $75 \mathrm{kN}^{10)}$

Table 5 Primary grains size and alpha laths length and width by interpass rolling load ${ }^{11)}$

\begin{tabular}{|c|c|c|c|}
\hline & As-built & $50 \mathrm{kN}$ & $75 \mathrm{kN}$ \\
\hline Primary $\beta$ grains & $3 \times 30 \mathrm{~mm}$ & $124 \mu \mathrm{m}$ & $89 \mu \mathrm{m}$ \\
\hline a laths length & $21.1 \mu \mathrm{m}$ & $15.5 \mu \mathrm{m}$ & $7.7 \mu \mathrm{m}$ \\
\hline a laths width & $1.2 \mu \mathrm{m}$ & $1.0 \mu \mathrm{m}$ & $0.7 \mu \mathrm{m}$ \\
\hline
\end{tabular}




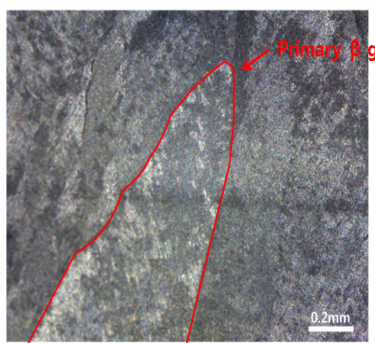

(a) Without peening

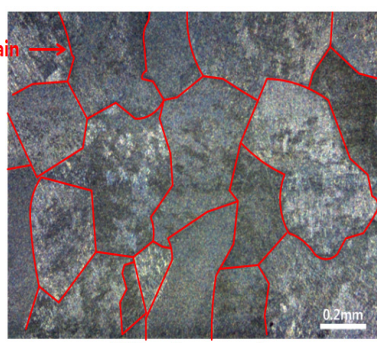

(b) With peening
Fig. 13 Optical microstructure of Ti-6Al-4V deposition with TIG welding (16x)

Table 6 Primary $\beta$ grain size of Ti-6Al-4V deposition with interpass peening

\begin{tabular}{|c|c|c|}
\hline & Without peening & With peening \\
\hline Primary $\beta$ grain size & $6 \times 19.1 \mathrm{~mm}$ & $460 \mu \mathrm{m}$ \\
\hline
\end{tabular}

ing을 미적용하면 $6^{*} 19.1 \mathrm{~mm}$, 적용하면 460 $\mu \mathrm{m}$ 로 primary $\beta$ grain의 크기가 현저히 감소되었다.

이 현상은 interpass rolling을 적용했을 때 ${ }^{9}$ 와 같이 interpass peening을 적용하면 소성변형으로 인하여 내부에 dislocation density가 증가하게 된다. 다음 층 을 적층할 때 가해진 열이 재결정을 발생시키고, 소성 변형으로 재료 내부의 저장된 에너지가 증가하여 핵생 성을 더욱 활발하게 일으키고, primary $\beta$ grain의 수 가 증가하여 $\beta$ grain의 사이즈가 감소하게 된다.

\subsection{2 a laths의 길이와 폭 비교}

Fig 14는 광학현미경으로 $\mathrm{Ti}-6 \mathrm{~A}-4 \mathrm{~V}$ 적층물을 800 배 로 확대한 미세조직이다. a laths의 길이와 폭을 측정 하였고 그 결과를 Table 7에 나타내었다. Interpass peening 미적용 시험편에서 a laths의 길이는 $25.5 \mu \mathrm{m}$, a laths의 폭은 각각 $1.4 \mu \mathrm{m}$ 으로 나타났다. Interpass peening 적용시험편은 a laths의 길이는 $14.8 \mu \mathrm{m}$, a laths 의 폭은 $0.8 \mu \mathrm{m}$ 로 interpass peening을 적용하면 a laths 의 길이와 폭이 모두 감소하는 경향을 보인다.

위의 결과는 interpass rolling의 하중이 증가할수록 a laths의 길이와 폭이 감소하는 것과 같은 경향으로 interpass peening을 적용하면 primary $\beta$ grain 크 기가 감소되고, a colony의 핵 생성 site가 증가하여 a 상의 성장이 서로 방해됨으로서 a lath의 길이와 폭이 모두 감소되는 것으로 판단된다.

\section{4. 결 론}

$\mathrm{Ti}-6 \mathrm{Al}-4 \mathrm{~V}$ 을 TIG용접 아크를 열원으로 한 금속AM 장치로 적층하여 interpass peening이 적층물의 기계

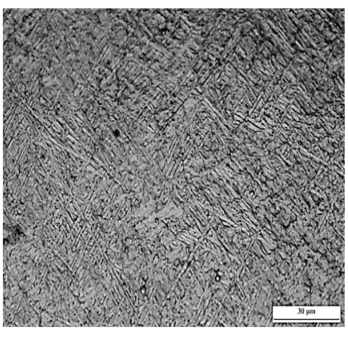

(a) Without peening

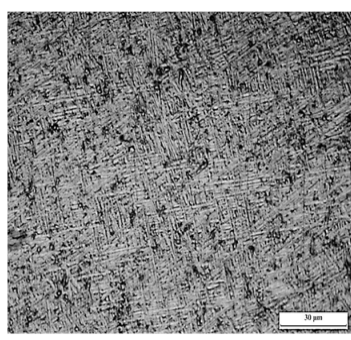

(b) With peening
Fig. 14 Optical microstructure of Ti-6Al-4V deposition with TIG welding $(800 \times)$

Table 7 a laths length and width of Ti-6Al-4V deposition with interpass peening

\begin{tabular}{|c|c|c|}
\hline & Without peening & With peening \\
\hline a laths length & $25.5 \mu \mathrm{m}$ & $14.8 \mu \mathrm{m}$ \\
\hline a laths width & $1.4 \mu \mathrm{m}$ & $0.8 \mu \mathrm{m}$ \\
\hline
\end{tabular}

적 성질에 미치는 영향에 대하여 검토한 결과 다음과 같은 결론을 얻었다.

1) $\mathrm{Ti}-6 \mathrm{Al}-4 \mathrm{~V}$ 의 금속 $\mathrm{AM}$ 에서 interpass plastic working 없이 적층할 경우 epitaxial grain growth 로 인하여 $\mathrm{z}$ 축의 항복/인장강도는 감소하게 되며, 최종 적층물은 기계적 성질의 이방성이 발생한다.

2) Interpass peening을 진행할 경우 interpass rolling과 마찬가지로 $z$ 축방향의 primary $\beta$ grain 크기는 감소되고, a colony의 핵생성 site가 증가하며, a laths 의 길이와 폭이 감소된다. 이로 인해 조직미세화로 연 신율의 감소 없이 항복/인장강도가 증가하여 재료의 이 방성이 감소하게 된다.

3) 본 연구의 interpass peening방식은 portable 방식으로 interpass rolling과 비교하여 금속 $\mathrm{AM}$ 의 현장에서 좀 더 유연하게 적용이 가능할 것으로 판단된 다. 또한 곡선과 다양한 벽 두께를 가지고 있는 적층물 의 제작에서 interpass rolling에 비해 interpass peening의 적용이 유리할 것으로 판단된다.

$$
\text { 후기 }
$$

본 연구는 부경대학교 자율창의학술연구비로 연구되 었습니다.

\section{References}

1. ASTM, F2792-12a, Standard Terminology for Additive Manufacturing Technologies

2. Jae-Gyu Byun, Sang-Myung Cho, Trend of Metal 3D Printing by Welding, J. of Welding and Joining, 34(4) (2016), 1-8 (in Korean) 
3. Kang, Min-Cheol, Dea-Hee Ye, and Geun-Ho Go, International Development Trend and Technical Issues of Metal Additive Manufacturing, J. of Welding and Joining, 34(4) (2016), 9-16 (in Korean)

4. Horii, Toshihide, Soshu Kirihara, and Yoshinari Miyamoto, Freeform fabrication of Ti-Al alloys by 3D microwelding, Intermetallics, 16(11) (2008), 1245-1249

5. Ma, Yan, et al., The effect of location on the microstructure and mechanical properties of titanium aluminides produced by additive layer manufacturing using in-situ alloying and gas tungsten arc welding, Materials Science and Engineering, A 631 (2015), 230-240

6. Baufeld, Bernd, and Omer Van der Biest, Mechanical properties of Ti-6Al-4V specimens produced by shaped metal deposition, Science and technology of advanced materials, 10(1) (2009), 015008

7. Szost, Blanka A., et al., A comparative study of additive manufacturing techniques, Residual stress and microstructural analysis of CLAD and WAAM printed Ti-6Al-4V components, Materials \& Design, 89 (2016), 559-567
8. Wang, Fude, Stewart W. Williams, and M. T. Rush, Morphology investigation on direct current pulsed gas tungsten arc welded additive layer manufactured Ti6A14V alloy, Int J Adv Manuf Technol, 57 (2011), 597-603

9. Martina, Filomeno, et al., Investigation of the benefits of plasma deposition for the additive layer manufacture of Ti-6Al-4V., Journal of Materials Processing Technology, 212(6) (2012), 1377-1386

10. Antonysamy, Alphons Anandaraj, Microstructure, texture and mechanical property evolution during additive manu facturing of Ti6A14V alloy for aerospace applications, University of Manchester for the degree of Doctor of Philosophy in the faculty of Engineering and Physical Sciences, (2012)

11. Colegrove, Paul, and Stewart Williams, High deposition rate high quality metal additive manufacture using wire+ arc technology, (2012)

12. Donoghue, J., et al., The effectiveness of combining rolling deformation with Wire-Arc Additive Manufacture on $\beta$-grain refinement and texture modification in Ti-6Al-4V, Materials Characterization, 114 (2016), 103-114 